\title{
Hablar la lengua del enemigo: la soledad del misionero en tierras calchaquíes
}

\author{
Christophe Giudicelli[1]
}

\begin{abstract}
Resumen
Este trabajo analiza una paradoja: la sincronía entre la adquisición tardía del idioma kakán por los misioneros y la brutal desaparición de la misión de Calchaquí, a mediados de los años 1660. Fue precisamente cuando los jesuitas hablaban por fin ese idioma, cuando eso ya no les sería de ninguna utilidad, por la extinción de la misión y deportación de sus neófitos. A su vez, esta paradoja lleva a interrogar el estatuto de ese idioma, hoy desaparecido, en la economía lingüística colonial. De lengua vehicular, terminó siendo lengua exclusiva del enemigo, identificada con un territorio (los Valles Calchaquíes) y una actitud rebelde. Su extensión fue menguando conforme progresaban los idiomas de comunicación colonial - en particular el quechua. Por fin, la dispersión de los habitantes fuera de los Valles dejó a los misioneros un conocimiento que ya sólo les serviría para prestaciones técnicas: para la transmisión de órdenes a los vencidos calchaquíes, alistados como "indios amigos" de la provincia.
\end{abstract}

Palabras clave: indios calchaquíes, misiones del Tucumán, idiomas coloniales.

Falando a língua do inimigo: a solidão do missionário nas terras calchaquís

\section{Resumo}

Este trabalho analisou um paradoxo: a sincronia entre a aquisição tardia do idioma kakán pelos missionários e o brutal desaparecimento da missão Calchaquí em meados dos anos 1660. Quando os jesuítas já falavam o idioma, esse conhecimento já não tinha nenhuma utilidade, pela extinção da missão e deportação de seus neófitos. Por sua vez, este paradoxo fez com que o estatuto de tal idioma, hoje inexistente, fosse investigado na economia linguística colonial. De língua veicular, terminou como o idioma exclusivo do inimigo, identificado como um território (os Valles Calchaquíes), e como uma atitude rebelde. Sua extensão foi diminuindo conforme a colonização avançava, promovendo-se os idiomas de comunicação colonial, particularmente o quéchua. Por fim, a dispersão dos habitantes fora dos vales deixou aos missionários um conhecimento que serviria apenas para propósitos técnicos: transmitir ordens à milícia dos calchaquies vencidos, alistados como "índios amigos" nas milícias da província.

Palavras-chave: índios calchaquies, missões de Tucumã, idiomas coloniais.

\section{Speaking the enemy language: the solitude of the missionary in calchaqui lands}

\section{Abstract}

This paper analyzes the paradoxical simultaneity of the late acquisition of the Kakan language by missionaries and the brutal disappearance of the Calchaqui mission in the mid-1660s. The Jesuits came to master the Indians' language exactly at the time when it stopped being of any use to them, due to the mission's extinction and due to the deportation of its neophytes. This paradox thus calls for further analysis of the status of the now extinct Kakan language within the colonial linguistic economy. The Kakan was a vehicular language and became the enemy's language, associated with a territory (the Calchaquies valleys) and with a rebellious attitude. Its expansion dwindled over the age of settlement, whose agents promoted the colonial communication languages, and quéchua in particular. Finally, the dispersion of the inhabitants outside the valleys restricted the missionaries' linguistic knowledge to technical use, when they needed to communicate orders to the defeated calchaquies, then "friendly Indians" in the province militia.

Keywords: calchaquíes Indians; Tucumán Province missions; colonial languages.

\section{Parlant la langue de l'ennemi: la solitude du missionnaire chez les Calchaquíes}

\section{Résumé}

Ce travail analyse un paradoxe: la simultanéité entre l'acquisition tardive de la langue kakan par les missionnaires et la disparition brutale de la mission Calchaquí, au milieu des années 1660. Au moment où les jésuites maîtrisaient cette langue, cette connaissance ne devait plus leur être d'aucune utilité, en raison de l'extinction de la mission et de la déportation de leurs néophytes. Ce paradoxe conduit en outre à interroger le statut du kakan dans l'économie linguistique coloniale. De langue véhiculaire, il finit par ne plus que la langue de l'ennemi, identifiée à un territoire (les Vallée Calchaquíes) et une attitude rebelle. Son extension se réduisit au rythme de la promotion des langues de communication coloniale - en particulier le quechua. Enfin, la dispersion des habitants en dehors des Vallées laissa à ces missionnaires une connaissance qui ne leur servit que pour des prestations de service techniques: la transmission des ordres aux vaincus calchaquís désormais «Indiens amis» dans les milices provinciales.

Mots-clés: indiens calchaquís, missions du Tucumán, langues coloniales. 
$\mathrm{E}$ ste breve trabajo buscó desentrañar una paradoja: la sincronía entre la adquisición, después de décadas de intentos infructuosos, del idioma kakán por parte de los misioneros de la Compañía de Jesús, y la desaparición de la misión de Calchaquí, a mediados de los años 1660.

Fue precisamente en el momento en que los jesuitas habían alcanzado por fin un buen manejo del idioma de los indios de su misión cuando este conocimiento ya no les sería de ninguna utilidad para la administración de la fe, por la extinción de la misión y deportación de sus neófitos.

A su vez, eso nos lleva a interrogar el estatuto de ese idioma desaparecido, originalmente hablado por aquellas poblaciones indígenas del área andina del Tucumán genéricamente rotuladas como "diaguitas" por los españoles y luego segmentadas en "diaguitas", "calchaquíes" y "pulares", en función del avance del frente de conquista y de la respectiva posición de cada uno de esos grupos en la economía de vigilancia de la provincia. ${ }^{1}$

Veremos que la que fuera la "lengua general" del Tucumán a finales del siglo XVI pasó a ser confinada geográfica y simbólicamente al enclave autónomo calchaquí, el cual resistió durante más de un siglo a todos los intentos de reducción. De lengua vehicular devino en lengua del enemigo, identificada con un territorio y una actitud rebelde durante toda la primera mitad del siglo XVII. Su extensión regional fue menguando a medida que se asentaba la colonización hispano-criolla, cuyos agentes promovieron activamente en su lugar los idiomas de comunicación colonial - y en particular el quechua - en las tierras que controlaban.

En estas condiciones, los últimos en aprender y practicar el kakán, además de sus locutores naturales e irredentos, fueron los jesuitas, por motivos que remiten a su actuación propia en la "Misión de Calchaquí", permanente entre el 1643 y el 1658. La guerra que se inició a partir del 1658 entre otras causas por las maniobras de Pedro Bohórquez, "el Inca del Tucumán”, al pronunciar la dispersión por la fuerza militar de las poblaciones hasta entonces autónomas del Valle Calchaquí, cambió radicalmente la situación. La dramática deportación de los indios, desparramados en una miríada de unidades de importancia variada en las zonas sumisas del Tucumán y más allá, dejó a esos misioneros sin misión con un conocimiento lingüístico que ya sólo les serviría para prestaciones técnicas: en particular oficiar de intérpretes en la tropa, en la transmisión de órdenes a la milicia de vencidos calchaquíes que componían lo esencial de las tropas de "indios amigos" de la provincia.

Empezaremos por el final de nuestra historia. La soledad — anunciada del último misionero de los llamados calchaquíes, el padre Hernando de Torreblanca, quién relató el ocaso dramático de su trabajo misionero en el

'Sobre este punto, véase Christophe Giudicelli, "Encasillar la frontera. Clasificaciones coloniales y disciplinamiento del espacio en el área diaguito-calchaquí (S. XVI-XVII)", Tandil (Argentina), Anuario IEHS, n. 22, 2007, p. 161-212. 
crepúsculo de su vida, en una "Relación histórica de Calchaqui", escrita en el 1696, pero olvidada e inédita hasta finales del siglo XX. ${ }^{2}$

Nos situamos a mediados de los años 1660. Las autoridades coloniales acaban de lograr finalmente lo que había sido una obsesión y un rompecabezas para el poder español desde hacía más de un siglo: aplastar definitivamente a los indios del Valle de Calchaquí, apoderarse del apetecido corredor valliserrano del Tucumán e integrar de fuerza a sus habitantes originarios en los sectores productivos de la provincia. Tras unas campañas militares particularmente duras, el gobernador Alonso de Mercado y Villacorta organizó de hecho un proceso inédito en la zona de desnaturalización sistemática de los habitantes de aquel enclave resistente. Un total de 12.000 personas, según sus cálculos, fue desparramada en los cuatro rincones de la provincia, pero también más allá hasta Santa Fe y las orillas del Río de la Plata. Una cifra que no incluye los cientos de "piezas" repartidas entre los soldados y que fueron a parar en distintos puntos del Virreinato. ${ }^{3}$

Si bien las campañas llevadas a cabo por Alonso de Mercado y Villacorta entre el periodo 1659 y 1666 no hicieron desaparecer propiamente hablando a los grupos indígenas de la región, al contrario de lo que se sostuvo durante mucho tiempo, ${ }^{4}$ aportaron sin embargo - desde el punto de vista del poder colonial - una solución final a la "cuestión calchaquí", al reducir definitivamente el territorio autónomo calchaquí a la obediencia colonial.

El caso es bien conocido: se suele atribuir la responsabilidad de este conflicto final a las maniobras rocambolescas de un personaje muy peculiar, un tal Pedro Bohórquez, "el Inca del Tucumán", "Pedro Huallpa,, "blanco y rubio", andaluz de nacimiento pero descendiente autoproclamado de los soberanos cuzqueños; ex-descubridor fracasado del Paitití, ex-presidiario en Valdivia precisamente por sus desastrosas andanzas peruanas; inventor de cañones descartables ${ }^{7} \mathrm{y}$, sobre todo, embaucador sin par. ${ }^{8}$ En el espacio de tres años, había logrado engatusar al mismo tiempo a los indios, a los principales mandamases de la provincia, al propio gobernador y, por fin, a los jesuitas. A los primeros prometía el final de la opresión, de las sacas, de la mita y de las exigencias de los encomenderos. A los

\footnotetext{
¿2Una primera versión salió publicada en 1984, pero la paleográfica que hace autoridad es la que publicó el Archivo General de la Nación (AGN) en 1999. Ambas a cargo de Teresa Piossek Prebisch. Hernando de Torreblanca, Relación Histórica de Calchaquí, Buenos Aires, AGN, 1999. [1696]

${ }^{3}$ AGN, Colección “Manuscritos relativos a América” de la Biblioteca Nacional, Leg. 181, n. 853. “Real cédula para que a los indios calchaquíes no se les considere esclavos, 20 diciembre 1674".

${ }^{4}$ Rodolfo Cruz, "El fin de la "ociosa libertad". Calchaquíes desnaturalizados a la jurisdicción de San Miguel de Tucumán en la segunda mitad del siglo XVII", in, Ana María Lorandi (comp.), El Tucumán Colonial y Charcas, Buenos Aires, FFyL - UBA, 1997, T. II, p. 215-261; Lorena Rodríguez, Después de las desnaturalizaciones. Transformaciones socio-económicas y étnicas al sur del valle Calchaquí. Santa María, fines siglo XVII-fines del XVIII, Buenos Aires, Editorial Antropofagia, 2008; Christophe Giudicelli, “De la déportation à l'invisibilisation: la "dénaturalisation" des Indiens Calchaquís (Nord-ouest argentin), XVIle-XXle siècle", in dossier "relocalisation et résilience autochtone", Recherches Amérindiennes au Québec 41(2-3), 2011, p. 61-82.

${ }^{5} \mathrm{AGl}$, Charcas 58, segundo cuaderno de los autos de Pedro Bohórquez, "Auto proveído por el gobernador Mercado y Villacorta, 8 de Julio de 1658", F. 53f-57v.

${ }^{6}$ AGI 122 , F 1 f, "Carta del gobernador Alonso de Mercado y Villacorta a la Audiencia de Charcas", 17-09-1657.

${ }^{7} \mathrm{AGI}, 122,1$ f, "Carta del Padre Juan de León al capitán Francisco de Nieva y Castilla, 24-06-1657".

8Sobre este personaje novelesco, véase Teresa Piossek Prebisch, Pedro Bohórquez, El Inca del Tucumán 1656-1659, Catamarca, Magma, 1999; Ana María Lorandi, De quimeras, rebeliones y utopías. La gesta de Pedro Bohorquez, Lima, Pontificia Universidad Católica del Perú, 1997.
} 
segundos, al contrario, les aseguraba que no sólo les iba a ganar la sumisión de los rebeldes, sino que además éstos le iban a revelar el secreto de las minas de oro y de plata que se esperaban encontrar en vano desde la misma fundación de la provincia. ${ }^{9}$ Para los últimos, pintaba por fin el cuadro ideal de una evangelización quizás sui generis pero efectiva, algo que nunca se había podido lograr a pesar de varias décadas de trabajo, y que estaba desesperando incluso a los más pacientes obreros de la Compañía. Varias Cartas Anuas habían lamentado en un estilo eufemístico el escaso resultado de la predicación: en el 1612 los padres “[...] cogen por ahora pequeño fruto [...]"; ${ }^{10}$ en el 1635 que “[...] no correspondía el fruto a las fatigas y celo de los ministros de Dios [...]"; ${ }^{11}$ la del 1641 evocaba así mismo "[...] la misión que siempre se les ha hecho, no correspondiendo el fruto con el trabajo". ${ }^{12}$ Por fin, la de los años 1653 y 1654, inmediatamente anteriores a la irrupción de Bohórquez, describía en términos similares: “[...] esta misión en que viven detenidos cuatro sacerdotes con más expensas de trabajos propios que fruto de las almas agenas",13 pero se mostraba infinitamente más pesimista contra “[...] los idólatras dese valle [...] que [...] no menos en lo phisico que en lo moral imitan del todo las costumbres de los brutos más indómitos".14 Por si fuera poco, seguía el redactor de la misma carta anua, parecían totalmente reacios que nunca a admitir la buena nueva, al punto de apostatar los pocos que hubieran podido dejarse convencer, "[...] volviendo al bomito que los vendría a lanzar a ellos en el infierno, con que se ven igualmente frustradas todas las amenazas que suelen convencer los ánimos más serviles".15

Con todo, si afloraba netamente un cierto desánimo en este último informe oficial, el vocabulario no se apartaba de lo que la jesuitic correctness dictaba. En cambio, la correspondencia privada de los misioneros que llevaban largos años viviendo en el Valle de Calchaquí, en San Carlos y Santa María, era muchísimo más violenta. El Padre Juan de León, por ejemplo, no se andaba con tantos rodeos cuando despotricaba contra "[...] unas bestias malditos delinquentes", en su carta al encomendero Francisco de Nieva y Castilla. Se felicitaba incluso, en un arrebato muy poco acorde con el tono benévolo y acompasado de las Anuas, de que: “[...] el capitán Pedro Calderón hisso muy bien en llebarlos en colleras y solo hisso mal en no llebarlos al cabo del mundo y que estubiessen y tapiados con prisiones que esto les conbendría más para su salvación".16

\footnotetext{
${ }_{9}^{9} \mathrm{AGI}$, Charcas 58, primer cuaderno de los autos que se seguían contra Pedro Bohorques, FF 4v-5v, “Carta de Pedro Bohorques al capitán Hernando de Pedraza, 21-04-1657”; AGI, 122, 1 f, Carta del Padre Juan de León al capitán Hernando de Pedraza, 24-06-1657.

${ }^{10}$ Anua de 1612, Documentos para la Historia de Argentina, Buenos Aires, Instituto de Investigaciones Históricas Dr. Emilio Ravignani, FFyL, UBA, 1927-1929, T. XIX, p. 515

"Anua de 1635-1637, Documentos para la Historia de Argentina, Buenos Aires, Instituto de Investigaciones Históricas Dr. Emilio Ravignani, FFyL, UBA, 1927-1929, T. XX, p. 401.

${ }^{12}$ Anua de 1641-1643, Cartas Anuas de la Provincia Jesuítica del Paraguay 1641 a 1643, p. 57. El "poco fruto" fue también aducido por el Provincial Nicolás de Mastrilli Durán para sopesar la oportunidad del primer desmantelamiento de la residencia de Calchaquí en 1623, "Carta al padre Nicolas Durán, Provincial Córdova, 1624", in Martín María Morales, A mis manos han Ilegado. Cartas de los P. Generales a la Antigua Provincia del Paraguay, Madrid-Roma, Universidad Pontificia de Comillas-I.HS.I, 2005, p. 312-313.

${ }^{13 H}$ Hernando de Torreblanca, Relación Histórica de Calchaquí, Buenos Aires, AGN, 1999. [1696], p. 136.

14/dem, Ibidem, p. 137.

15/dem, Ibidem, p. 143

${ }^{16} \mathrm{AGI}, 122,1$ f, "Carta del Padre Juan de León al capitán Francisco de Nieva y Castilla, 24-06-1657”.
} 
Para darle más fuerza evocadora al medio, algo radical y bastante poco caritativo que preconizaba para la salvación de esos indios diaguitas que habían sido los principales protagonistas del "Gran Alzamiento de los años 1630-1640",17 iba hasta declarar que "dejarlos en su libertad es como darle un cuchillo a un loco frenético".18

Sea lo que fuere, los misioneros contaron desde el principio entre los más fervientes partidarios del peculiar Inca, sin duda en parte porque entreveían con su llegada la posibilidad de lograr la tan ansiada conversión de los indios, y pensaban aprovecharse del ascendiente que él había logrado entre sus disipados catecúmenos. De los cuatro misioneros, el padre Juan de León era sin lugar a dudas el más convencido por Bohórquez, y el menos prudente a la hora de referirse a él en su correspondencia como "nuestro amigo el general don Pedro", 19 "nuestro buen amigo" ${ }^{20}$ e incluso "nuestro inga". ${ }^{21}$ Lo cierto es que ese padre no parece haber sido el más ilustrado, si debemos confiar en el dictamen de los catálogos trienales secretos elaborados por la misma compañía, ${ }^{22}$ lo que explicaría su falta de prudencia en unas cartas que pide por cierto a sus destinatarios que las quemen y que terminaron en los autos judiciales levantados contra Bohórquez. ${ }^{23}$ El catálogo secreto del 1651 le atribuye por ejemplo un ingenium mediocre, un judicium exiguum, una prudentia parva y una experientia rerum parva, una evaluación algo preocupante confirmada en todo punto en el de $1656 .{ }^{24}$ Tal vez haya influido también en su juicio furibundo contra los indios el hecho de que, al haber nacido en Santiago del Estero en $1617,{ }^{25}$ había sido criado si no en el odio, por lo menos en la desconfianza que profesaban generalmente todos los hispano-criollos contra los indios diaguitas y calchaquíes rebeldes.

Notaremos sin embargo que, a grandes rasgos, sus hermanos de religión, sin duda menos exaltados - y mejor notados por sus superiores — habían seguido las mismas orientaciones y respaldado con términos más pausados, pero sin más reserva las maniobras de tan extraño personaje. El superior de la misión, el padre Eugenio de Sancho, le había escrito al gobernador en este sentido, ${ }^{26}$ mientras que Hernando de Torreblanca, también criollo e hijo de un encomendero de

\footnotetext{
${ }^{17}$ Aníbal Montes, "El gran alzamiento diaguita”, Revista del Instituto de Antropología, Universidad del Litoral, Rosario, n. 1, 1961, p. 81-159.

${ }^{18} \mathrm{AGI}, 122,1$ f, “Carta del Padre Juan de León al capitán Francisco de Nieva y Castilla, 24-06-1657”.

$19 / \mathrm{dem}$, Ibidem.

${ }^{20} \mathrm{AGI}, 122,1$ f, "Carta del Padre Juan de León al capitán Hernando de Pedraza, 24-06-1657".

21/dem, Ibidem.

${ }^{22}$ Para un estudio pormenorizado de los catálogos, y, más allá, de los misioneros de la provincia jesuita del Perú, véase Aliocha Maldavsky, Vocaciones inciertas. Misión y misioneros en la provincia jesuita del Perú en los siglos XVI Y XVII, Madrid, CSIC, 2012.

${ }^{23} \mathrm{AGI}, 122$, F 2 v, "Carta del Padre Juan de León al capitán Francisco de Nieva y Castilla, 24-06-1657".

${ }^{24}$ Se encuentran en ARSI, Paraquaria 4-1, F 167 et sqs y 192 et sqs.

${ }^{25}$ Catálogo trienal de 1644, ARSI, Paraquaria 4-1, F. 142 f et sqs.

${ }^{26} \mathrm{AGI}$, Charcas 58, Primer cuaderno de los autos que se seguían contra Pedro Bohórquez, FF 3f-3v, "Carta del P. Eugenio de Sancho", 19-04-1657.
} 
Córdoba, ${ }^{27}$ había oficiado en todas circunstancias como intermediario bilingüe, defendiendo los intereses del estrambótico proyecto neo-incaico de Bohórquez.

\title{
Intérprete y mediador: la voz del Inca
}

Para alcanzar tamaña fuerza de persuasión, don Pedro Huallpa debió necesariamente dar prueba de una elocuencia descomunal, que había deslumbrado - o más bien encandilado - a todos sus interlocutores. Ahora, curiosamente, si bien se expresaba en castellano ante los encomenderos, las autoridades civiles y los padres de la Compañía de Jesús no sólo no manejaban el kakán — el idioma de los indios que lo habían acogido - sino que tampoco podían expresarse en quechua, la lengua del Tawantinsuyu, cuya renaciente dinastía afirmaba encarnar. Un hecho que suscita el asombro - eso sí a posteriori - del misionero solitario del que estamos hablando, Hernando de Torreblanca:

\author{
En el espacio de tres años, había logrado engatusar \\ al mismo tiempo a los indios, a los principales \\ mandamases de la provincia, al propio gobernador \\ $y$, por fin, a los jesuitas
}

\begin{abstract}
[Pedro Bohórquez] intentó el alzamiento de los indios, y alzarse con el nombre de Inga: y lo que es de admirar, que para esta maraña y fantasía, él no sabía la lengua general de los Ingas, que es la Quichua, ni la del país de Calchaquí, valiéndose sólo de un intérprete. ${ }^{28}$
\end{abstract}

Es cierto que Torreblanca tenía algunas razones para "admirarse" de semejante paradoja: como lo vimos, había sido uno de los missi dominici de Bohórquez y se había empleado con celo para favorecer la instalación del inca andaluz en el mero corazón del Valle de Calchaquí, en Tolombón, cerca de su misión de San Carlos, convenciendo por si fuera poco al gobernador de dejarlo llevar oficialmente el título de "Inca", además del de "lugarteniente general, justicia mayor y capitán a guerra en Calchaquí, sus términos y jurisdicción" ${ }^{29}$ Torreblanca se extraña unos 30 años después de los hechos en un relato que despunta una franca amargura ante lo que es fuerza llamar un desastre: es que se habían encaminado tan mal las cosas que todo había acabado con la ruina de la Misión de Calchaquí, el retorno de la guerra y,

\footnotetext{
${ }^{27}$ Había nacido en Córdoba el 13 de septiembre de 1613 y era hijo de Juan de Torreblanca, encomendero portugués sospechoso de ser judaizante, lo que había suscitado una investigación sobre la limpieza de su sangre. Martín Morales, op. cit., p. 416. Otros datos biográficos en la Carta Anua de 1689-1700, resumida por Carlos Page, "La evangelización jesuita del Valle Calchaquí. Hacia la idealización de un nuevo hábitat jesuíticocalchaqui", Tempo da Ciência, vol. 17, n. 33, $1^{\circ}$ semestre 2010, p. 44 (p. 25-55).

${ }^{28}$ Hernando de Torreblanca, Relación Histórica de Calchaquí, Buenos Aires, AGN, 1999. [1696], p. 83.

${ }^{29} \mathrm{AGI}$ Charcas 58, Acta de la segunda junta celebrada el 07-08-1657 en San Juan Bautista de la Ribera (Pomán), AGI, Charcas 121, Nombramiento otorgado a Pedro Bohorques, San Juan Bautista de la Ribera 08-08-1657.
} 
finalmente, la desnaturalización de los antiguos neófitos, lo que pronunciaba por la misma ocasión el fracaso definitivo de los jesuitas.

Ciertamente era para asombrarse: efectivamente, Pedro Bohórquez sólo se dirigía a los indios diaguitas por medio de un intérprete, un tal Lorenzo Pisapanaco, ${ }^{30}$ cuyo nombre indica que procedía de las inmediaciones de Pomán, ya que Pisapanaco fuera un pueblo de indios sometido desde hacía tiempo, lo que puede explicar la familiaridad que tenía con el castellano.

Ahora bien, si miramos las cosas más detenidamente, nos damos cuenta de que ese Lorenzo no era el único intérprete de aquella tragicomedia andina. En las negociaciones tripartitas entre las autoridades españolas, Bohórquez y los indios, el verdadero intérprete, plebiscitado por todas las partes, no era otro que el propio padre Hernando de Torreblanca, presente en todas las reuniones y firmantes de los principales documentos que entronizaron a Bohórquez, le permitieron oficialmente en el Valle, con todo y mandato. La participación del misionero en las juntas celebradas durante unos 15 días, entre el 30 de julio y el 13 de agosto del 1657, en la ciudad de Pomán, fue realmente clave:

Sehicieron varias conferencias en juntas [...] a mímellamaron alas más de ellas como intérprete que, aunque había lenguas que podían asistir, no eran capaces para dar a entender las materias, porque no también no sabían la lengua española para poder decir lo que se les proponía ni tenían conocimiento de los países y poblaciones de Calchaquí. ${ }^{31}$

Lo que omite escribir el buen padre, en su Relación Histórica, es que era también portador de un mandato de Bohórquez y de los indios. Participó también de la aparatosa ceremonia con la que Bohórquez hizo entrada en esa ciudad con su séquito de varios centenares de indios armados, para reunirse con el gobernador y con las autoridades de Pomán. ${ }^{32}$

\section{Intérprete y capellán millitar: la voz de la pacificación}

Un año después, la situación había cambiado por completo. Se había entendido que Bohórquez estaba fomentando un "sublevamiento general" - y que su presencia permitía una recomposición de una trama de alianzas maltrechas por las relaciones coloniales. El hecho es que desde la jurisdicción de La Rioja - y en concreto el valle sometido de Famatina ${ }^{33}$ - hasta las reducciones de los Pulares, que servían desde hacía tiempo a los encomenderos de Salta, ${ }^{34}$ circularon flechas de alianzas, las cuales que, según parece, llegaron incluso a Casabindo y a las inmediaciones

\footnotetext{
30Hernando de Torreblanca, Relación Histórica de Calchaquí, Buenos Aires, AGN, 1999. [1696], p. 41. ${ }^{31} / \mathrm{dem}$, Ibidem.

32Piossek Prebisch, Pedro Bohórquez, El Inca del Tucumán 1656-1659, Catamarca, Magma, 1999; p. 114 et sqs, reproduce varios documentos inéditos sobre esta entrada. Da en particular la lista de los caciques presentes en el encuentro. Idem, Ibidem, p. 109, nota 181 (es una transcripción de AGI, Charcas, 121).

${ }^{33}$ “Carta del Cura de Famatina, D. Juan Gedeón de Guzmán, al señor Maestre de campo Juan Gregorio Basan de Pedraza, Alcalde ordinario de los Santos, 20-04-1658", Pablo Pastells, Historia de la Compañía de Jesús en la provincia del Paraguay, Madrid, Victoriano Suárez, 1912, vol. 2, p. 535-536.

${ }^{34}$ Christophe Giudicelli, "La raya de los pulares. Pouvoir colonial et quadrillage de lespace social dans le Valle de Calchaquí", In: Jimena Paz Obregón Iturra, Luc Capdevila et Nicolas Richard (eds), Les indiens des frontières coloniales. Amérique australe, XVle au XXe siècle, Rennes, PUR, 2011, p. 27-58.
} 
de Potosí, ${ }^{35}$ algo inédito desde hacía varias décadas. Lógicamente, los jesuitas cayeron en desgracia a ojos de Bohórquez, quien los expulsó manu militari, saqueó sus misiones, ${ }^{36}$ y dio inicio a las operaciones de guerra propiamente dichas, con ataques en regla contra el fuerte de San Bernardo, camino de Salta, San Miguel de Tucumán, el fuerte de Andalgalá, con el saqueo de varias estancias y la destrucción de las minas del Acay, en el camino que llevaba del Valle de Calchaquí al altiplano. ${ }^{37}$ Ante el fracaso de su ofensiva militar, Bohórquez optó por desaparecer del Tucumán, dejando frente a frente a indios y españoles (Figura 1). ${ }^{38}$

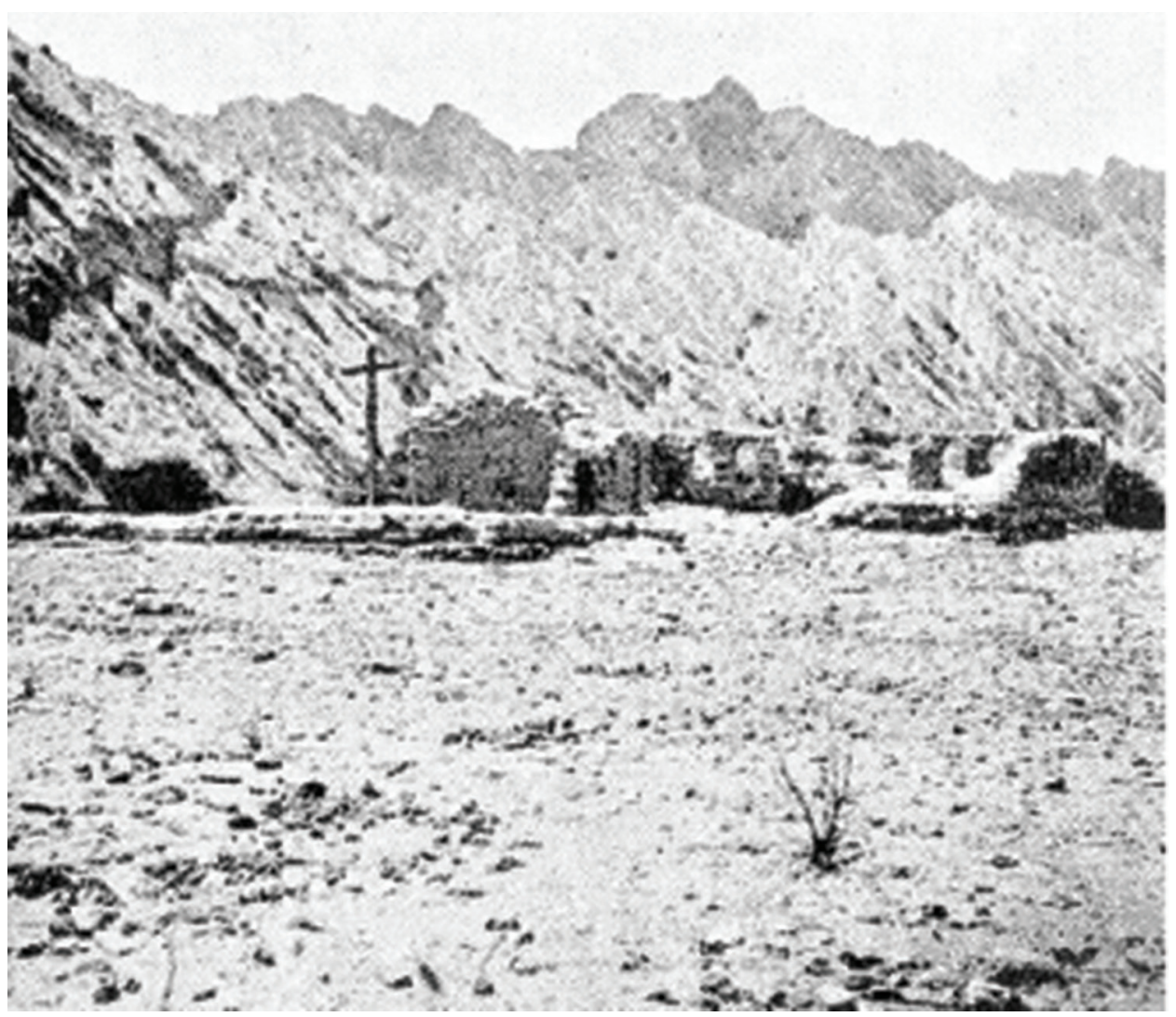

Figura 1. Ruinas de la misión de San Carlos de Tucumanahao.39

Ya desengañados y privados del espejismo de una conversión more incaico, a los misioneros no les quedó más remedio que abandonar definitivamente el

\footnotetext{
${ }^{35}$ Hernando de Torreblanca, Relación Histórica de Calchaquí, Buenos Aires, AGN, 1999. [1696], p. 45. 36/dem, Ibidem, p. 49-53.

${ }^{37}$ Idem, Ibidem, p. 52-53.

${ }^{38}$ Aceptó una propuesta oficial de indulto, pero después de varias peripecias fue llevado directamente a Lima, donde sería posteriormente ejecutado en la cárcel. Ana María Lorandi, De quimeras, rebeliones y utopías. La gesta de Pedro Bohorquez, Lima, Pontificia Universidad Católica del Perú, 1997, p. $299-311$.

${ }^{39}$ Foto de Juan Bautista Ambrosetti, "Por el Valle Calchaqui", Anales de la Sociedad Científica, XLIV, Buenos Aires, 1897, p. 289-305. Según varios autores, San Carlos de Tucumanahao había sido la sede de la misión de San Carlos destruida a instancias de Bohórquez, y sería distinta de la primera misión de San Carlos de Samalamao donde tuviera lugar el primer intento misional. Para una discusión sobre este punto, véase María Teresa Iglesias, Luís Capeletti, Fausto Guerrero, María Victoria Massa, y Liliana Zamagna, "Investigaciones preliminares en el sitio San Carlos (Valle Calchaquí, Salta)", Revista Escuela De Historia, vol. 1, n. 6, 2007.
} 
Valle de Calchaquí y dedicarse a otra de sus funciones: oficiar de capellanes militares en las tropas de pacificación, contra sus ex-catecúmenos. ${ }^{40}$ Para esta tarea, el superior de la finada misión, Eugenio de Sancho, y el propio Hernando de Torreblanca se pusieron a disposición de las autoridades en las ofensivas lanzadas en el invierno del 1659. El primero acompañó las columnas militares alistadas en La Rioja y Londres, ${ }^{41}$ mientras que Torreblanca ya no se apartó más del gobernador Mercado y Villacorta, quien hizo de él una pieza clave de su dispositivo de pacificación. Es que por su buen conocimiento de la lengua del enemigo, era la persona más indicada para llevar a cabo las negociaciones y, concretamente, dictar las condiciones de rendición impuestas por el gobernador: "Mi trabajo en eso era continuo, sirviendo de intérprete para persuadirle su conveniencia, por estar con más expedición en la lengua para representarles los inconvenientes de su disipación, si no salían" ${ }^{42}$

Además, como conocía muy bien a los indios cuya rendición exigía ahora, por haber vivido más de 15 años entre ellos, sus competencias "culturales" hacían de él un excelente consejero militar para encontrar condiciones aceptables por los vencidos y convencerlos de dejar las armas:

[...] el señor gobernador me concedió una gracia y fue que a ningún indio se hiciese, aunque lo cogiesen prisionero, castigo de quitarle el cabello, azotarlo o desgarrarlo; y su señoría me lo concedió y así se hizo. ${ }^{43}$

En otras palabras, el ex-misionero había pasado a ser un elemento imprescindible de las fuerzas de pacificación. Jugó un rol clave en la crucial negociación que llevó a que los calchaquíes de Tolombón y Paciocas, que siempre habían tenido un papel central en las guerras pasadas, cambiaran de alianza bajo la presión militar y se alistaran como "indios amigos" al lado de las tropas tucumanas contra sus vecinos Quilmes. ${ }^{44}$ Participó también activamente al final de esta primera campaña, en la identificación de los grupos vencidos y en su desnaturalización.

Entre el 1660 y 1664, el gobernador Mercado y Villacorta tuvo que dejar la gobernación del Tucumán por la del Río de La Plata, por lo que se detuvo el proceso de pacificación drástico que había emprendido. Al término de su mandato, fue destinado de nuevo a su antiguo puesto, con la misión explícita de terminar la labor iniciada cinco años antes, "sacando" a todos los indios aún sublevados, y en particular los de Quilmes y del Valle Yocavil. ${ }^{45}$ Entre las primeras

\footnotetext{
${ }^{40}$ En este caso, es probable que el celo que pusieron en participar en las operaciones militares tuviera que ver con la consciencia de su responsabilidad en la situación, pero este tipo de participación fue una constante en todas las operaciones de pacificación en las "fronteras" de la América española. Véase por ejemplo Christophe Giudicelli "Indios amigos y normalización colonial en las fronteras americanas de la Monarquía Católica (Tucumán, Nueva Vizcaya, S. XVI-XVII)", In: José Javier Ruiz Ibáñez (Coord.), Las milicias del rey de España. Sociedad, politica e identidad en las Monarquías ibéricas, Madrid, FCE, 2008, p. 349-377.

${ }^{41}$ Hernando de Torreblanca, Relación Histórica de Calchaquí, Buenos Aires, AGN, 1999. [1696], p. 66.

${ }^{42}$ Idem, Ibidem, p. 71.

${ }^{43} / \mathrm{dem}$, Ibidem.

44/dem, Ibidem, p. 70

${ }^{45}$ Roxana Boixadós, "El fin de las guerras calchaquíes. La desnaturalización de la nación yocavil a La Rioja (1667)", Corpus n. 1, 2011 (en línea). Christophe Giudicelli, "De la déportation à linvisibilisation: la "dénaturalisation" des Indiens Calchaquís (Nord-ouest argentin), XVIle-XXle siècle", in dossier "relocalisation et résilience autochtone", Recherches Amérindiennes au Québec 41(2-3), 2011.
} 
medidas tomadas para preparar esta segunda campaña, Mercado reasumió al jesuita criollo y lenguaraz que tan buenos resultados le había permitido lograr:

Prevínose [Alonso de Mercado] en el Puerto, y sacó provisión, que para la campaña que había de hacer de esta conquista, el P. Provincial de la Compañía le había de dar dos padres por el tiempo que durase, y uno fuese el P. Hernando de Torreblanca por haber tenido allí muchos años de asistencia, y haberle acompañado después del alzamiento: ser lengua y tener conocimiento del gentío. ${ }^{46}$

En este caso, sus competencias particulares - "ser lengua y tener conocimiento del gentío" - no sólo servirían para las negociaciones de paz, sino que también le fue asignada una posición particular en la cadena de mando. Era encargado de traducir al kakán las órdenes y demás instrucciones militares transmitidas por el gobernador a los contingentes de "indios amigos" de Tolombón y Paciocas en las campañas contra sus antiguos aliados. Según su propio testimonio, Torreblanca era el único que lo pudiera hacer: "Nunca me faltó qué hacer con los indios porque no había otra lengua que en el idioma de su lengua les diese a entender lo que se pretendía, y el gobernador quería que ejecutasen". ${ }^{47}$

El manejo de la lengua de los calchaquíes ya "amigos" alcanzado por este misionero cambió lo que se supone sería su vocación primera: si bien siguió desempeñando funciones espirituales en los distintos colegios que contaba la Compañía de Jesús en la provincia, ${ }^{48}$ siguió también dedicando tiempo y energía para las tareas de vigilancia y de pacificación cuando era movilizado por las autoridades. La razón que aduce en su Relación es que nadie como él manejaba el kakán. Y como los grupos calchaquíes reinstalados en el Valle de Choromoros ${ }^{49}$ habían sido transformados en la principal milicia auxiliar contra los indios del Chaco, en los linderos orientales cada vez más tumultuosos del Tucumán, le era fuerza acompañarlos en sus expediciones, para que no se quebrara la cadena de mando:

Estando en Salta dio el mocobí en la almena de Esteco y fue necesario ir a socorrer aquella plaza; y a toda priesa acompañando a esta facción: y como los que ayudaban inmediatamente a esto eran los Calchaquís, no podía faltar, atareado a darles a entender lo que se les ordenaba, y fuera de su país no había quien les hubiese comprendido. ${ }^{50}$

Aquí cabe un comentario: si bien la participación de los padres a las campañas militares más cruentas eran parte íntegra de sus atribuciones y no sólo en el escenario americano - en este caso reconocen explícitamente "imitar

\footnotetext{
${ }^{46}$ Hernando de Torreblanca, Relación Histórica de Calchaquí, Buenos Aires, AGN, 1999. [1696], p. 85. ${ }^{47}$ Idem, Ibidem, p. 86.

${ }^{48}$ Fue rector del Colegio de Salta después de las campañas militares. ARSI, Paraquaria 4-1, F 217 v.

${ }^{49}$ Cristina López de Albornoz, "Las desnaturalizaciones Calchaquíes y sus efectos en las poblaciones trasladadas al Valle de Choromoros", Anuario de estudios americanos, Tomo XLVII, 1990, p. 29-42.

${ }^{50}$ Hernando de Torreblanca, op. cit., p. 71 y 85-86.
} 
la capellanía castrense de Flandes"51 - , lo que sorprende y nos interesa más directamente en el caso presente es que la tarea asignada al padre Torreblanca haya sido de índole más práctica - lingüística - que espiritual, y, más aún, que le haya sido asignada casi por defecto. Dicho de otro modo, lo que llama la atención es que el gobernador no haya tenido a mano a nadie más que a un intérprete de sotana, ya entrado en años, ${ }^{52}$ para sus campañas militares. Que no se hubiera encontrado a nadie, por ejemplo, para escoltar a los miles de indios Quilmes deportados hasta el puerto de Buenos Aires y más precisamente la reducción de la Exaltación de la Santa Cruz de los Quilmes, la cual dio origen a la actual ciudad bonaerense de Quilmes. ${ }^{53}$ Algo que le pesó particularmente a Torreblanca ya que había postulado para ese puesto que le fue negado: "los indios fueron convoyados más de 200 leguas y reducidos con cura clérigo que ni los entendía ni sabía su lengua.. ${ }^{4}$

Aun pensando que Torreblanca, en el crepúsculo de su existencia, estaba animado por la voluntad de contrarrestar su papel bochornoso en la ruina de la misión de Calchaquí subrayando su eximia capacidad para las lenguas amerindias, llegamos a la conclusión de que, sencillamente, no había nadie en ese momento en condiciones de ejercer medianamente bien el cargo de intérprete del kakán hacia el castellano y viceversa. Otro factor que tendería a confirmar esta hipótesis: se sabe que Mercado y Villacorta era "poco afecto a la Compañía", por lo que es de suponer que su elección fue dictada ante todo por consideraciones prácticas. A su vez, eso nos conduce casi mecánicamente a plantear otra pregunta: ¿cómo puede ser que nadie o casi nadie haya sido capaz de hablar ese idioma fuera de sus locutores naturales, es decir los propios diaguitas?

\section{El kalkán, "lengua general"}

Un primer reflejo incitaría a pensar que se trataría de un idioma poco extendido y marginal, pero ésta es una hipótesis que hay que se abandonar inmediatamente por dos razones. La primera es de índole coyuntural: la extensión de las deportaciones que acabamos de evocar - no menos de 12.000 personas según los cálculos del mismo gobernador ${ }^{55}$ — hace probablemente de la población kakanoparlante la población indígena más importante de la región en un momento en que los grupos indígenas de las zonas controladas del Tucumán habían alcanzado

\footnotetext{
51“Carta Anua del Provincial Simon de Ojeda, años 1658-1680, In: Hernando de Torreblanca, Relación Histórica de Calchaquí, Buenos Aires, AGN, 1999. [1696], p. 132: "[...] y así fueron despachados para este fin tres de los misioneros que habían estado entre los calchaquíes, imitándose la capellanía castrense de Flandes". ${ }^{52} \mathrm{ARSI}$, Paraquaria 4-1, F. 117 et sqs, según el catálogo trienal del 1631, contaba ya más de 50 años para la segunda campaña de desnaturalizaciones, ya que nació el 13 de septiembre de 1613.

${ }^{53}$ Miguel Angel Palermo y Roxana Boixadós, "Transformaciones en una comunidad desnaturalizada: los Quilmes, del Valle Calchaquí a Buenos Aires”, Anuario del Instituto de Estudios Históricos y Sociales, v. 6, 1991, p. 13-42; Florencia Carlón, “La reducción “Exaltación de la Cruz de los indios Quilmes”: un caso de relocalización étnica en Pampa a fines del siglo XVII", Mundo agrario, vol. 8, n. 15, 2007 (en línea).

${ }^{54}$ Hernando de Torreblanca, Relación Histórica de Calchaquí, Buenos Aires, AGN, 1999. [1696], op. cit., p. 111

${ }^{55}$ Antonio Larrouy, Documentos del Archivo de Indias para la historia del Tucumán, vol.1 Santuario de Señora del Valle, T.I, Buenos Aires, 1923, p. 276.
} 
su nadir demográfico. La segunda razón es que sencillamente sabemos que el kakán era, al contrario, un idioma extremadamente extendido a la llegada de los colonos españoles, sin duda practicado más allá de su área principal del corredor interandino del Tucumán y de parte del la llanura tucumano-santiagueña. En el 1582, Pedro Sotelo Narváez, en un informe dirigido al licenciado Cepeda, presidente de la Audiencia de Charcas, la presenta inclusive como una lengua vehicular: "[...] hablan una lengua que llaman diaguita, general entre ellos, aunque hay otras cuatro lenguas que llaman tonocoté, indama, sanavirona y lule".56

Ahora bien, que un español acostumbrado a la realidad del virreinato del Perú hable de "lengua general" es todo menos anodino. Da la medida, en todo caso, del lugar preeminente y de la función de esa lengua. Con todo, uno podría no confiar en la sensibilidad lingüística de un vulgar espadachín de esa lejana provincia - cierto es que los colonos del Tucumán se conocían más por su brutalidad que por su amor al arte y a las letras. Será más difícil cuestionar la palabra del primer misionero despachado por la Compañía para evangelización del Tucumán. Tanto más cuanto que éste, era nada menos que uno de los pioneros jesuitas del Perú Alonso de Barzana, discípulo de Juan de Ávila, llegado al Perú en el mismo barco que el virrey Toledo, en 1569, veterano de las primeras doctrinas de la Compañía, Santiago del Cercado, Huarochirí y Juli. Tanto más cuanto que fue precisamente el redactor de las primeras gramáticas y catecismos en quechua y aymara, decidida en la primera congregación provincial de enero del $1576 .{ }^{57}$ Barzana contaba de hecho entre los más insignes lingüistas de la Compañía, y al parecer manejaba excelentemente los principales idiomas indígenas de la actual Bolivia, que no sólo había practicado siendo misionero sino que los había enseñado en su calidad de titular de la cátedra diocesana de quechua, aymara y puquina de Potosí desde 1583, una enseñanza descentralizada de la Universidad de Lima donde se había instituido en el 1580. ${ }^{58}$

En 1593, al anunciar la redacción de un vocabulario en cinco lenguas, escrito junto con su compañero Pedro de Añasco, que tenía la particularidad de ser mestizo, nacido en Chachapoyas, describe el kakán en estos términos:

[...] la tercera lengua deste vocabulario es aún más general que ésta [la tonocoté] porque la habla la mayor parte de la gente que sirve a Santiago y todo el valle de Catamarca y todos aquellos muchos millares que conquistó ahora el gobernador en lo de Londres y todo el valle de Calchaquí que conquistó los años pasados. ${ }^{59}$

\footnotetext{
56Roberto Levillier, Nueva crónica de la conquista del Tucumán, v. 3, p. 324-332.

${ }^{57}$ Charles O'Neil, Joaquín M. Domínguez, Diccionario histórico de la Compañía de Jesús, Institum historicum, SI \& Universidad Pontificia Comillas, Madrid, 2001, p. 362-363.

${ }^{58}$ Real Cédula para que en las cátedras de la universidad de los Reyes se establezca una lengua general de los indios, para que los sacerdotes que les han de administrar tengan la inteligencia de dicha lengua. 23-091580 Pablo Pastells, Historia de la Compañía de Jesús de la provincia del Paraguay, Madrid, 1912, p. 20-22 NB sigue otra del 5-10-1580: "para que la cátedra de lengua general de los indios que se lee en la universidad de los Reyes se instituya en todas las partes de las Indias donde hay Audiencias y Cancillerías Reales (para que los sacerdotes que salgan a las doctrinas hayan cursado en ella)".

59“Carta de Alonso de Barzana al Provincial, 1593, 20-12, In: “Anua de la provincia del Perú", Monumenta Peruana, T.V., op. cit., p. 383, et sqs.
} 
Al año siguiente confirmaría el carácter general de esa lengua:

Las lenguas más generales que tienen los indios de esta tierra son la caca, tonocoté, sanavirona. La caca usan todos los diaguitas y todo el valle de Calchaquí y el valle de Catamarca y gran parte de la Nueva Rioja, y los pueblos casi todos que sirven a Santiago, asílos poblados en el río del Estero como otros muchos que están en la sierra. Esta lengua está esperando la diligencia de nuestros obreros, porque tiene muchos millares de infieles sin haberse podido acudir a ellos. Ay echo arte y vocabulario de esta lengua. [...] A quien cupiese la suerte de apóstol diaguita, y sabiendo bien la lengua caca, paseare de espacio todos los pueblos de la Nueva Rioja y el Valle de Famatina y el de Calchaquí, y el de Catamarca, y todas esas naciones que yo no e visto, él dará cuenta $[\ldots]$ de cuantos pueblos son $[\ldots] .{ }^{60}$

Se habrá entendido que, para Barzana y sus contemporáneos inmediatos, se trataba de una lengua extremadamente extendida, que el calificativo de general parecía homologar al quechua para el Perú, al guaraní para el Paraguay y el Río de La Plata o al náhuatl para el México central. Hubiera sido por lo tanto lógico - y práctico - establecer unos mecanismos más o menos institucionalizados de interpretación. Es fuerza constatar que, al contrario, no sólo el paso de un idioma a otro nunca dejó de ser fuente de problemas durante todo el periodo considerado sino que fue paulatinamente abandonado en provecho del uso de otros idiomas de comunicación, en particular el quechua, el cual pasó a ser el idioma de comunicación preferencial con las poblaciones indígenas, en las relaciones laborales, la justicia y la administración. Nuestra hipótesis es que al ser el kakán ante todo la lengua del enemigo, su uso se restringió progresivamente a dos campos especializados - si bien según modalidades distintas aunque complementarias - , que remiten ambos al programa de sumisión y de transformación social que el poder colonial estaba implementando: la vigilancia y el control militar por un lado, la misión por el otro.

\section{El quechua, "lingua franca"}

Desde los albores de la provincia del Tucumán, por motivos que remiten al origen geográfico inmediato - peruano - de los colonos y de sus servidores indígenas, el quechua hizo las veces de segundo idioma colonial, antes de convertirse en la primera lengua de comunicación con los indios "domésticos", quienes tuvieron que aprenderla cuando no lo conocían. Como es sabido, existirían islotes lingüísticos quechua en algunas partes del Noroeste Argentino, en particular en la región de Santiago del Estero. También es posible que, puntualmente, por la presencia pasada de mitmaquna impuesta por los incas en la

60“Carta del padre Alonco de Barçana al p. Juan Sebastián, provincial 1594, O8-09 (desde Asunción)", Monumenta Peruana, T.V., op. cit., p. 568-580, et sqs. 
región, algunos grupos hayan tenido cierto conocimiento de la lengua imperial, además de la suya propia.$^{61}$ Con todo, no parece haber sido el caso de las poblaciones kakanoparlantes, que ocupaban un confín aparentemente muy conflictivo del ex-Tawantinsuyu. Para estas poblaciones "diaguitas", la generalización del quechua a partir de finales del siglo XVI es claramente de origen colonial y tuvo una consecuencia que nos interesa directamente aquí: la comunicación entre las distintas instancias coloniales y los indios siguió muy a menudo un doble filtro lingüístico kakán-quechua-español.

Existen algunas menciones, sobre todo al principio del período, de interpretación simple, por ejemplo el caso de la toma de posesión por parte del encomendero Juan de Abreu de los indios del pueblo de Amimaná, en 1592:

Cuando comparecieron ante las autoridades [...] un yndio llamado ynga y un yndio llamado Panizay, cuyas declaraciones quedan registradas [...] por mi el presente escribano (un tal Pedro Hernández) que sé mui bien la lengua diaguita [...] el que agrega por si acaso que el dicho indio me entendió bien. ${ }^{62}$

Sin embargo, las más veces, las declaraciones de los indios seguían un recorrido más largo. Cuando en el 1622, el obispo del Tucumán, Julián de Cortázar, visitó los Valles Calchaquíes, por ejemplo, los testimonios fueron re-transcritos "por lengua de diego Laines indio ladino", es decir, en este caso - y era muy común - que hablaba quechua, era "ladino en la lengua general del inga": "lo cual el dho diego laines yntérprete dixo en lengua general del ynga decian los dhos yndios la qual dha lengua entiende y yo ablo".63

O sea que las declaraciones de los calchaquíes, que se expresan en kakán, vienen traducidas por el ladino Diego Laínez al quechua y luego pasadas al castellano por el escribano, un tal Juan de Higueras. ${ }^{64}$ De modo que en el Tucumán como en el resto del virreinato del Perú, se hizo lo necesario para que el quechua hiciera las veces de lingua franca. Se tomaron incluso medidas voluntaristas para extender su uso entre indios e hispano-criollos. El Sínodo del 1602 preveía explícitamente por ejemplo que los curas debían predicarles a los indios en quechua "[...] porque ya gran parte de los indios reçan y ban siendo ladinos en dicha lengua" ${ }^{65}$ Por su parte, las élites locales presionaban para que las máximas autoridades recayeran en alguien que tuviera ya cierta experiencia americana - por no decir un criollo - y, para empezar, que manejara la lengua general. En este sentido, el cabildo de San Miguel de Tucumán pedía

\footnotetext{
${ }^{61}$ Ana María Lorandi, "Evidencia en torno a los mitmaqkuna incaicos en el N.O. argentino", Anthropologica, n. 9, diciembre de 1991, p. 213-243.

${ }^{62}$ AGN, 1596, 14-09, "Posesión de los indios encomienda del pueblo de Amimaná a Juan de Abreu".

63“Expediente de la visita que hizo el obispo de Tucumán, Doctor Julián Cortázar en el Valle Calchaquí”, In: Roberto Levillier (ed.), Papeles eclesiásticos del Tucumán, Madrid, ed. De Juan Pueyo, 1926, vol. 1, p. 315.

${ }^{64} \mathrm{AHPC}$, Escr. 1a, leg. 15, exp. 12, "Martin de Mojica contra Alonso Martin de Zorita sobre indios 1602". Fueron encontrados varios casos similares en el Tucumán, y no sólo en tierras diaguitas, por ejemplo, la toma de posesión de la encomienda de Martín de Mojica, en la jurisdicción de Córdoba, se hace también "en la lengua natural" hacia "un muchacho de su servicio que conoce la lengua general del Piru que yo conozco".

${ }^{65}$ Citado por Estela Noli, "Indios ladinos del Tucumán colonial: los carpinteros de Marapa”, Andes, n. 12. 2001, p. 141.
} 
en 1613: “[...] que el governador sepa la lengua general del ynga que muchos de los yndios de estas provincias entienden, particularmente los que sirven en los pueblos y casas de los españoles".66

Si las comunicaciones directas quedaban relativamente limitadas, se impuso sin embargo una "ladinización" (hacia el quechua) de los indios incorporados en la esfera colonial. Abundan los ejemplos. Citemos un caso límite, el de otra toma de posesión de dos indios -probablemente "piezas" 67 - cuando la fundación en el corazón del Valle Calchaquí del efímero fuerte de Nuestra Señora de Guadalupe, en 1635. Ésta se hizo [...] en la lengua general del Perú que entienden y hablan los dichos indios [...].$^{68}$ Ahora bien, los dos prisioneros son "Luís Guallanchay, cacique principal del pueblo de Guatungasta, y Diego indio latino del pueblo de Fiambala". Igual que en el caso ya citado de Lorenzo Pisapanaco, se trataba de indios diaguitas de encomienda, procedentes de la jurisdicción de La Rioja, refugiados en el enclave rebelde calchaquí al favor del "Gran Alzamiento", lo que explicaría su condición de "ladinos".

Se encontró una situación muy comparable entre los indios pulares, el otro segmento separado del grupo genérico inicial llamado "diaguita" por los hispano-criollos, como consecuencia de su sumisión y su temprana incorporación en los distintos dispositivos económicos y “civilizatorios" impuestos por las reglas de convivencia colonial. El hecho de que tal o cual indio maneje el quechua es muchas veces la marca de un contacto regular con los españoles, mucho más que la señal de una antigua incorporación al mundo incaico que hubiera impuesta la lengua imperial en esos lejanos y conflictivos pagos. Esos contactos no faltaban, entre los

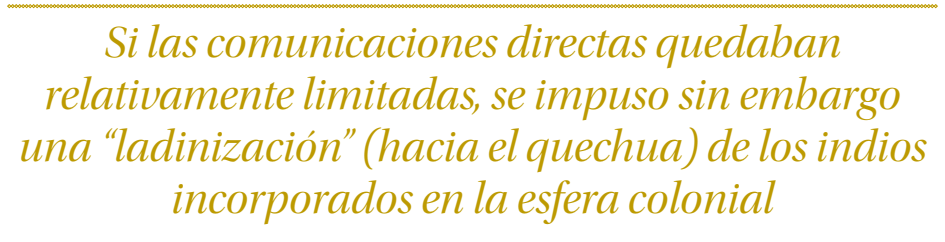

turnos de mita que los llevaba a trabajar en las ciudades de la provincia, en las tierras de su encomendero y a veces hasta el centro de la Audiencia de Charcas, para arriar mulas. El análisis sincrónico del manejo respectivo de la "lengua general del inga" por grupos que hablan kakán a veces emparentados entre sí, pero separados por lo que es fuerza llamar una frontera de guerra demuestra sin lugar a dudas

\footnotetext{
${ }^{66}$ Levillier, op. cit., p. 100-103, subrayado nuestro.

${ }^{67}$ Es decir indios presos "en justa guerra" y depositados por un tiempo determinado al servicio de un español. Sobre esta práctica, véase Gaston Doucet, "Sobre cautivos de guerra y esclavos indios en el Tucumán", Revista de historia del derecho, n. 16, 1988, p. 59-152.

${ }^{68}$ Servicios del capitán don Gregorio de Luna y Cárdenas, AHPC-Escribanía II-4 n. 24; Aníbal Montes, Encomiendas de indios diaguitas documentadas en el archivo histórico de Córdoba, Córdoba, 1986, p. 10.
} 
el carácter determinante de la relación colonial en este proceso de aprendizaje. ${ }^{69}$ Así mismo, los estudios sobre los grupos indígenas de la falda oriental de la Sierra del Aconquija, controlada desde fechas tempranas por los encomenderos de San Miguel de Tucumán, da constancia de este avance del quechua entre grupos de habla kakana que se evidencia de forma particularmente clara después de las desnaturalizaciones de los años 1659-1665 y la relocalización por la fuerza de grupos sacados del área valliserrana en la misma región.

La visita del cura Verdugo Garnica en el 1685 demuestra clarísimamente que tenían un conocimiento del quechua notoriamente inferior, teniendo el mismo idioma materno. ${ }^{70}$ Estela Noli, en su estudio sobre el pueblo de Marapa, que dependía directamente de San Miguel de Tucumán, muestra también el abismo que separaba a los habitantes de este pueblo, todos ladinos en quechua, y los grupos recién desnaturalizados, a quienes les costaba defenderse en una situación en la que el uso del quechua era estratégico. ${ }^{71}$

\section{El kakán, lengua del enemigo/hablar la lengua del enemigo}

Si la extensión colonial del quechua en el Tucumán fuera parte de un proceso general, quedaría por entender porqué el kakán, del que vimos que era una lengua vehicular a nivel regional a la llegada de los hispano-criollos, terminó marginado y prácticamente excluido de las comunicaciones coloniales, al punto que, para mediados del siglo XVII, los únicos que lo pudiesen hablar, fuera de los indios, eran el puñado de misioneros que vivían entre ellos. La explicación apunta sin lugar a dudas hacia el estatuto simbólico de esta lengua, en relación con la posición de sus locutores en la economía de vigilancia de la provincia. Se afirmó como la lengua del enemigo y quedó geográficamente identificada con el enclave resistente calchaquí, por lo menos desde el primer alzamiento de 1562 que dio por tierra con la totalidad de las ciudades fundadas en el área valliserrana. Lo que sin lugar a dudas acrecentó la sospecha fue la suerte de los habitantes de la ciudad de Córdoba de Calchaquí: fueron masacrados, con la excepción de las mujeres y niños, capturados y absorbidos entre los indios. Algunos de esos niños habían sido reconocidos años más tarde entre las "piezas" llevadas en colleras, después de las expediciones militares, totalmente

\footnotetext{
${ }^{69}$ Rodolfo Cruz estudia esta cuestión entre Tafíes y Amaichas, "La "construcción" de identidades étnicas en el Tucumán colonial: los amaichas y los tafies en el debate sobre su "verdadera" estructura étnica”, In: Ana María Lorandi (comp.), El Tucumán colonial y Charcas, Buenos Aires, FFyL - UBA, 1997, T. II, p. 253-282.

${ }^{70}$ Larrouy, Documentos del Archivo de Indias para la historia del Tucumán, vol. 1 Santuario de Señora del Valle, T.l, Buenos Aires, 1923, p. 360, et sqs.

${ }^{71}$ Estela Noli, "Indios ladinos del Tucumán colonial: los carpinteros de Marapa”, op. cit.. El quechua se extiende de forma muy elocuente a los principales sectores de actividad y termina contaminando el español cotidiano, al nombrar categorías esenciales para la economía. El informe del Padre Juan Ximénez sobre los abusos de los pobleros de las encomiendas de Londres denuncia por ejemplo que: "Todos los días de la semana el poblero y camayo de cualquiera pueblo, al amanecer hace juntar a los curacas y fiscales los dichos indios e indias" para repartirles un guarço de lana para hila (citado en Laura Quiroga, "Las granjerías de la tierra: actores y escenarios del conflicto colonial en el valle de Londres (gobernación del Tucumán, 1607-1611)", Surandino Monográfico, segunda sección del Prohal Monográfico, vol. 2, n. 2, 2012 (en línea).
} 
indianizados. Habían perdido su idioma materno, lo que causó no poca turbación entre los colonos de la provincia. ${ }^{72}$

Hablar el kakán podía incluso ser considerado como un marcador de infidelidad, desde el momento en que su práctica rebasaba el marco estricto de las relaciones coloniales. El caso más conocido - pero muy poco documentado - es el del escándalo causado por Juan Bautista Muñoz, hijo de uno de los fundadores de Londres y de San Miguel de Tucumán, hombre rico y poderoso, benefactor de la Compañía de Jesús, ${ }^{73}$ Juan Bautista Bernio. Ese Muñoz se había tirado al monte y había elegido refugiarse con sus mancebas indígenas en tierra de guerra antes que hacer vida con su legítima esposa, según los sanos principios de la moral cristiana, como se lo exigía el gobernador de entonces, Juan Ramírez de Velasco.

En un informe de fines de 1586, escribía éste último que:

[...] el cabildo e vecinos y otras personas de la ciudad de San Miguel del Tucumán de esta gobernación me han dado aviso que un mozo llamado Juan Baptista Muñoz hijo de Juan Baptista Bernio, vecino de esta ciudad sin caussa alguna se fue de esta dicha ciudad a meter entre yndios enemigos y esta fortalecido con ellos en el [...] esta con dañado pecho de hazer mal e como ladino en las lenguas de los naturales desta governacion querer hazer daño con ellos a los españoles de la dha ciudad. ${ }^{74}$

Como lo vemos, el hecho de hablar la lengua de los enemigos parecía ser un agravante, y ubicaba a ese ¿individuo? en una situación de abierta rebelión, homologable a la de los "yndios enemigos", es decir, para la fecha, la totalidad de la población kakanoparlante de los altos valles del Tucumán, ${ }^{75}$ donde cautivos - y amantes - españoles corrían el riesgo de perder su castellano.

Nuestra hipótesis es que fuera de relaciones puntuales de tipo administrativo, el trato de la interlocución entre "calchaquíes" e hispano-criollos fue rápidamente acotado a la política de pacificación y sumisión, y reservada a dos tipos de especialistas: militares y religiosos, por razones distintas pero en parte convergentes, tanto más cuanto que aquí como en todas las zonas de conquista, los misioneros llegaron con la tropa, y las misiones se hicieron en la estela de las "entradas". En nuestro caso, el primer jesuita despachado desde el Perú en

\footnotetext{
${ }^{72}$ Christophe Giudicelli, “El conquistador y su sombra. Silencios en la conquista del Tucumán (siglo XVI)”, In: Christophe Giudicelli, Gilles Havard y Salvador Bernabéu Albert (eds), La indianización. Cautivos, renegados, "hommes libres" y misioneros en los confines de América (Siglos XVI-XIX), Madrid, Doce Calles, 2013, p. 137-160. ${ }^{73} \mathrm{AHT}$, protocolos, vol. 1, FS 1-2vta, "Don Juan Bautista Bernio alguacil del Santo Oficio de la Inquisición, hace donación a favor de la Compañía de Jesús de un solar de tierras que cae a la parte del río de la ciudad", San Miguel de Tucumán, 9-12-1588.

74“Comisión dada por el gobernador Don Juan Ramírez de Velasco al capitán Hernán Mexia Miraval para que fuese a prender a Juan Bautista Muñoz 24-1-1586", In: Roberto Levillier, Probanzas de méritos y servicios de los conquistadores, Madrid, Sucesores de Rivadeneyra, vol. 2, 1919-1920, p. 602. Subrayado nuestro.

${ }^{75}$ FueraSan Miguel, la única ciudad que había sido fundada era Salta, en 1582, pero, según Rámirez de Velasco, "aunque ha cinco años que se pobló, no le sirve indio, y se sustenta con grandísimo trabajo, por no haber más de un fuerte en que están 30 o 35 soldados, con solo la esperanza de que se ha de salir á hacer la guerra, sin llevar salario ni gaje de S. M., el teniente y los soldados, á cuya causa pasan mucha necesidad", "Carta del gobernador Don Juan Ramírez de Velasco al virrey del Perú, conde del Villar, 04-06-1587, In: Roberto Levillier, Gobernación del Tucumán, Papeles de gobernadores en el siglo XVI, vol. 2, Madrid, Juan Pueyo, 1920, p. 209-213.
} 
conocer a unos indígenas de idioma kakán, el ya evocado Alonso de Barzana, no lo hizo como misionero, sino como capellán de las tropas lanzadas desde Salta para una campaña particularmente dura en los valles, y que duró varios meses. ${ }^{76}$ Fue también a instancia de las autoridades civiles y eclesiásticas, y bajo la protección de los soldados de esa misma ciudad, que la Compañía pudo desarrollar su labor misionera entre los indios, primero bajo la forma de misiones volantes y luego con una presencia permanente en dos ocasiones: los periodos de $1617-1624^{77}$ y 1643-1658.

\section{Altibajos lingưísticos de la evangelización}

Los misioneros tenían un interés por así decirlo técnico o profesional en adquirir un conocimiento del kakán: debían inculcar la Buena Nueva a los indios y convencerlos de abrazar una vida conforme con los preceptos de la "policía cristiana".

Como lo vimos, el trabajo lingüístico de los misioneros en tierras diaguitas parece corresponder con la excelencia de la que se ufanan tanto los historiadores de la Compañía. El famoso padre Barzana, a menudo llamado "el apóstol del Tucumán”, y su compañero Pedro de Añasco habían redactado desde los primeros años un catecismo y un vocabulario que deberían haber facilitado el trabajo misionero, y que parecían ya surtir efecto tan pronto como en 1594:

Un solo padre enpesó a casar, confessar, catequissar en ella; aunque muy principiante bautizó muchos dellos, y casó y confesó también otros muchos que en toda su vida savian qué era confesarse. ${ }^{78}$

Para esas fechas, la práctica se orientaba en el Tucumán como en todas las tierras misionadas por la Compañía hacia la administración multitudinaria de sacramentos, sin que los padres se preocuparan demasiado de saber si entendieron bien las confesiones o si los indios pudieron apreciar todas las sutilezas del misterio de la eucaristía. ${ }^{79}$ Sin embargo, a pesar de esos principios prometedores, los progresos en kakán de los siguientes obreros fueron más bien tímidos.

\footnotetext{
76“Carta del gobernador Juan Ramírez de Velasco a S.M., 13-03-1588”, In: Roberto Levillier, Gobernación del Tucumán, Papeles de gobernadores en el siglo XVI, vol. 2, Madrid, Juan Pueyo, 1920, p. 235-239.

${ }^{77}$ María Florencia Amigó proponía la fecha de 1622 para el primer abandono de las doctrinas jesuíticas, El desafío de Calchaquí. Un puñado de jesuitas entre un mar de indios. La intervención de la Compañía de Jesús en el Valle Calchaquí (siglos XVI-XVII). Tesis (Licenciatura en Ciencias Antropológicas) - Facultad de Filosofía y Letras, Universidad de Buenos Aires, 2000. Sin embargo, un informe del Provincial Pedro de Oñate de 1623 señala que la residencia de Calchaquí "tiene cinco padres y un hermano. Dales su Mgtd para su sustento 1,200 pesos de renta con que apenas se puede sustentar el dicho numero. No tienen iglesias ni ornamentos bastantes ni alhajas sino mucha pobreza". ARSI, Paraquaria 4-1, F. 89 v. Otro informe adjunto al catálogo trienal de 1626 por el Provincial Nicolás Mastrilli Durán reporta que el colegio de Salta se encarga de "las misiones de Calchaquí, de las que les hemos salido por falta de sustento" (ARSI, Paraquaria 4-1, F 110 f). Del documento citado en la nota 12 podemos inferir que la misión permanente desapareció probablemente en 1624 .

${ }^{78 “ C}$ Carta del padre Alonco de Barçana al p. Juan Sebastián, provincial 1594, 08-09 (desde Asunción)”, Monumenta Peruana, Roma, institutum historicum Societati lesu, 1970, T.V., p. 568-580, et sqs.

${ }^{79} \mathrm{Los}$ bautizos multitudinarios se practicaban también en el mismo momento en la naciente provincia de los Tepehuanes en el Norte de la Nueva España. Véase los informes del padre Jerónimo en las Cartas Anuas de 1596 y 1597. Vicente García Torres (ed.), Documentos para la historia de México, México, 1854-1857, 3 vol.
} 
La Carta Anua de 1609, menciona que "el padre Horacio [Morelli] ba muy adelante en la lengua y con mucho cuydado catequiza y habla en ella [...]" ${ }^{80}$ Sin embargo, a pesar de que la Compañía pudo establecerse en dos residencias fijas entre 1617 y 1624, la Carta Anua de 1626-27 evoca aún el trabajo de aprendizaje de los misioneros: “[...] atiéndese a aprender la lengua chaca y tomar de memoria un catecismo breve que hemos hecho para que todos catequicemos [...]". ${ }^{81}$ Diez años más tarde, a mediados de los años 1630, parece incluso que bajó el nivel. Ya ni siquiera se aplican los misioneros a chapurrear sermones y tratar de descifrar confesiones, ya ni siquiera pueden comunicar, "[...] siendo a veces menester usar de uno y dos intérpretes de diferentes lenguas por no entender la propia suya los Padres así para instruirlos y hazerles capaces como para confessarlos". 2

\section{Hasta el mensaje apostólico difundido por los capellanes jesuitas durante las campañas de "pacificación," tenía que pasar por uno o varios intérpretes}

Hasta el mensaje apostólico difundido por los capellanes jesuitas durante las campañas de "pacificación", tenía que pasar por uno o varios intérpretes:

"[los padres] a todos los dexaron bien ynstruidos en las cosas de la fe, valiéndose de buenos intérpretes por ser su lengua muy reveçada y no entender muchos la que generalmente corre y hablan los Padres".83

La pregunta que podríamos plantear a esta altura es por qué los jesuitas, en contradicción con su reputación en materia de aprendizajes de idiomas indígenas $^{84}$ (y no sólo en el Nuevo Mundo), dejaron tan pobre impresión en este escenario tucumano. No alcanza con la excusa de la dificultad intrínseca del kakán, "lengua ([...)] exquisidamente bárbara y en la pronunciación asperíssima". ${ }^{85}$ La explicación es a todas luces de otra índole, y remite por lo menos a dos factores: la delicada posición de la Compañía Compañía en las primeras décadas

\footnotetext{
80 Paraquaria, 8, ff 30f-32 f, reproducido en "Documentos para la historia de Argentina", Buenos Aires, Instituto de Investigaciones Históricas Dr. Emilio Ravignani, FFyL, UBA, 1927-1929,. T. 19, p. 75-77. 81"Documentos para la historia de Argentina", Idem, T. XX, p. 178-183.

${ }^{82}$ Anua de 1635-37, “Documentos para la historia de Argentina”, T. 20, p. 400-415

${ }^{83}$ Anua de 1632-1634, Cartas Anuas de la provincia jesuitica del Paraguay, Academia Nacional de la Historia, Buenos Aires, 1990, p. 53

${ }^{84}$ Una reputación ampliamente sino usurpada por lo menos magnificada en varias regiones. Véase para el Norte de México Bernd Hausberger, "Política y cambios lingüísticos en el noroeste jesuítico de la Nueva España", Relaciones, n. 78, 1999, p. 59-77.

${ }^{85}$ Anua de 1632-1634, Cartas Anuas de la provincia jesuítica del Paraguay, Academia Nacional de la Historia, Buenos Aires, 1990, p. 72-73.
} 
del siglo XVII por su oposición radical al servicio personal, y la situación ideológica ya evocada del kakán.

En cuanto al primer factor, está claro que la posición de los jesuitas de la naciente provincia del Paraguay contra el servicio personal no granjeó a sus religiosos un desmesurado amor por parte de los primeros interesados en que se perpetuase, es decir los encomenderos, quienes detentaban la realidad del poder en el Tucumán. Los jesuitas criticaron duramente el servicio personal, generalizado y regulado en el Tucumán desde las ordenanzas tomadas en 1576 por el gobernador Gonzalo de Abréu, ${ }^{86}$ incluso antes de las nuevas edictadas por el visitador y Oídor de la Audiencia de Charcas, Francisco de Alfaro. Los "pareceres" extremadamente críticos, presentados en 1609 por el teólogo de la Compañía Juan Pérez de Menacho, fueron firmados por los misioneros del Tucumán: Horacio Morelli, Luís de Hoyos y Juan Darío. ${ }^{87}$ Las Cartas Anuas redactadas en la década de 1610 por el padre Diego de Torres Bollo condenan asimismo en términos muy duros la codicia y la crueldad de los encomenderos, ${ }^{88}$ lo que los enemistó con parte de las élites locales. A la larga, hizo insostenible la persistencia de su "Residencia de Calchaquí", finalmente abandonada hacia 1624 después de un informe asesino del obispo Julián de Cortázar que terminó de desacreditar la acción de los misioneros, alineándose con la posición de los encomenderos. ${ }^{89}$

Creemos sin embargo que el segundo factor fue todavía más importante para explicar el escaso progreso de los jesuitas entre los calchaquíes, y su dificultad por aprender su lengua. Tratándose de la lengua del enemigo interior, de una lengua confinada a la vez geográfica y políticamente, los misioneros parecen haberse dedicado - o haber sido limitados - ante todo a su tarea política. Un comedido explícito desde el principio: fueron llamados "para pacificar y reducir los indios" ${ }^{90}$ Después de los casi 15 años del "Gran Alzamiento", hubo que volver a empezar. Se decidió privilegiar la reinstalación de las misiones permanentes en la región valliserrana, instalando a cuatro padres en las antiguas doctrinas de San Carlos y Santa María. El objetivo contemplaba por supuesto aspectos religiosos, pero es de destacar que la iniciativa fue una vez más tomada por las autoridades civiles y por el obispo del Tucumán, Fray Alonso Maldonado, movidos por inquietudes más temporales de vigilancia y de "pacificación" más suave. Lo que extrañó al obispo, con cierta razón, fue la notable impreparación de los jesuitas, y en particular su nulidad lingüística:

\footnotetext{
${ }^{86}$ El texto de las ordenanzas se encuentra reproducido en Levillier, Gobernación del Tucumán, Papeles de gobernadores en el siglo XVI, vol. 2, Madrid, Juan Pueyo, 1920. T. 2, p. $32-45$.

${ }^{87}$ AGN, Fondo Biblioteca Nacional, n.5621 (leg. 840), “Pareceres sobre las principales ordenanzas del gobernador del Tucumán Gonzalo de Abreu, relativas al servicio personal de los indios de aquella gobernación”.

${ }^{88}$ Anua de 1613, In: Documentos para la historia Argentina, T. 19, Buenos Aires, Instituto de Investigaciones Históricas Dr. Emilio Ravignani, FFyL, UBA, 1927-1929, p. 197.

89“Expediente de la visita que hizo el obispo de Tucumán, Doctor Julián Cortázar al en el Valle Calchaquí, O210-1622, 11-1622", Roberto Levillier, (ed.), Papeles eclesiásticos del Tucumán, Madrid, ed. De Juan Pueyo, 1926, vol. 1, p. 308-323.

${ }^{90}$ Anua de 1624, Documentos para la historia Argentina, T. 19, p. 75.
} 
cuando se pidió “[...] a la Compañía de Jesús que volviese a entrar al dho valle; hallose sin quien entendiese la lengua, que es singular".91

Por lo tanto, hubo que se formar sobre la marcha nuevos obreros. Ahora bien, nada mejor para ello que otro tipo de especialista: los padres destinados de oficio hicieron sus primeras armas en el fuerte del Pantano, una especie de mega-reducción militarizada donde habían sido deportados y concentrados los indios diaguitas, considerados más culpables a finales de los años $1630 .{ }^{92}$ Allí, para su aprendizaje y ministerio, los misioneros bisoños pudieron contar, entre 1639 y 1643, con la enseñanza bruta de un personaje que conocía bien la lengua de esos presos de guerra, por razones obvias, un tal Antonio Calderón: era nada menos que el responsable militar del fuerte en cuestión. ${ }^{93}$ Hernando de Torreblanca, que aún no era el gran intérprete que se jactaría de ser después le rinde un sentido homenaje a su maestro en su Relación:

En este tiempo conseguimos que un gran lenguaraz, llamado Antonio Calderón, sirviéndonos de intérprete, reviese el vocabulario de la lengua calchaquí cotejándolo con los vocablos de la lengua que allí se habla, que en muchas cosas de la pronunciación varía, aunque en lo substancial es lo mismo. ${ }^{94}$

Con todo, la adquisición del diaguita del Valle Calchaquí distó aparentemente de ser un paseo de salud. A pocos meses de su instalación en San Carlos, Torreblanca se quejaba de la dificultad que aún sentía para comunicar:

[...] no muestran mucho gusto los indios en que aprendamos su lengua. Es también dificultosa de reducir a método; aunque los primeros padres trabajaron, como muestran sus escritos, es cosa muy dimidiada. ${ }^{95}$

Habría que esperar principios de la década siguiente para que la Compañía pudiera vanagloriarse por fin de las dotes de sus representantes en tierras calchaquíes, quienes "alcançaron perfectamente su difícil y bárbaro lenguaje" falta de resultado espiritual alguno. En definitiva, Torreblanca tuvo que esperar la llegada de Pedro Bohórquez para dar toda la medida de su talento de "lengua", durante las negociaciones mantenidas entre las diferentes partes. Cruel paradoja: fueron precisamente estas negociaciones las que precipitaron el final de la misión y reorientaron al solitario misionero bilingüe hacia tareas castrenses.

\footnotetext{
${ }^{91}$ Carta del obispo Fray Melchor de Maldonado, 13-09-1658, In: Larrouy, Documentos del Archivo de Indias para la historia del Tucumán, vol.1 Santuario de Señora del Valle, T.I, Buenos Aires, 1923, p. 202.

${ }^{92}$ Ana María Lorandi y Sara Sosa Miatello, "El precio de la libertad. Desnaturalización y traslados de indios rebeldes en el siglo XVII", Memoria Americana, vol. 1, n. 1, 1991, p. 7-28.

${ }^{93}$ Otros documentos subrayan en los mismos términos las aptitudes de este personaje: "declaración de Antonio Calderón, cabo del fuerte del Pantano dijo que conoce muy bien a estos indios porque es criollo nacido y criado en la dicha ciudad de San Juan de la Ribera y que este testigo es el mejor lenguaraz de la lengua de los dichos indios diaguitas malfines. Aníbal Montes, "El gran alzamiento diaguita", Revista del Instituto de Antropología, Universidad del Litoral, Rosario, n. 1, 1961, “Probanza para la entrada a Malfín”, p. 152. ${ }^{94}$ Hernando de Torreblanca, Relación Histórica de Calchaquí, Buenos Aires, AGN, 1999. [1696], p. 98.

${ }_{95}$ Pablo Pastells, "Carta del Provincial de la Cia de Jesús Fco de Lupercio de Zurbano a SM 1644, $19-12$ (desde Bs Aires)", Historia de la Compañía de Jesús en la provincia del Paraguay, Madrid, Victoriano Suárez, 1912, vol. 2 t. 2, p. 96-101.

96“Carta Anua 1653-1654", In: Jaime Cortesão, Manuscritos da coleção de Angelis, t. II: Jesuítas e bandeirantes no Itatim (1596-1760), Rio de Janeiro, Biblioteca Nacional do Rio de Janeiro, 1952, p. 139.
} 


\section{Conclusiones}

Hablar la lengua del enemigo, ser por fin el perito más buscado de propios y ajenos sólo le habrá permitido al misionero solitario acompañar a sus locutores hacia la desaparición de esa lengua. Una vez vencidos y atomizados en los cuatro rincones del Tucumán y del Río de la Plata, las poblaciones diaguitas, por una razón difícil de determinar la ciencia cierta pero que tiene que ver sin duda tanto con la economía simbólica de las relaciones coloniales como con las nuevas necesidades nacidas de su nueva condición de vencidos, terminaron perdiendo su idioma. Reducidos en establecimientos coloniales haciendas o pueblos de indios - en los que convivirían no sólo con otros ladinos de diversos orígenes sino también, cada vez más, con presos mocovíes y tobas capturados durante las malocas organizados en el Chaco, tuvieron que apoyarse en nuevas formas comunes de expresión. El quechua, sin duda, cada vez más el español, cuando no una sabia mezcla mestizada en la que los términos kakán ocuparon cada vez menos espacio.

Haría falta una investigación más fina para seguir realmente esta evolución. Un buen indicador tal vez sea el seguimiento sistemático de los archivos relativos a las encomiendas y a los archivos judiciales posteriores a las campañas de desnaturalización, para ver qué tratamiento se les reserva a los desnaturalizados. Una mirada muy rápida a las actas de la visita del Oidor Luján de Vargas a las encomiendas de Tucumán, ${ }^{97}$ La Rioja y Jujuy, ${ }^{98}$ donde muchos de los calchaquíes habían sido "reducidos", visita casi contemporánea de la escritura de la Relación Histórica de Calchaquí, suscita dos comentarios. Primero, esos indios aparecen ya como "calchaquís", sin más precisión sobre el lugar exacto de su procedencia. Segundo, si bien se tuvo a bien nombrar para la visita a dos intérpretes - el escribano Lorenzo Pinto y el protector de naturales Diego de Salazar y Benavidez (oriundo de La Rioja) -, no se indica en ningún lado qué idioma se supone que hablan. Ahora bien, en varios casos son interrogados de forma conjunta unos indios "calchaquís" y "mocovíes",99 de los que sabemos que no hablaban la misma lengua. Cabe preguntarse cómo, en esas circunstancias, esos indios pudieron tratar de transmitir sus quejas a los magistrados. Aunque es difícil en este caso preciso determinar la ciencia cierta, está claro que este tipo de dispositivo legal fue de los que influyeron en la adopción por parte de los vencidos de las lenguas de comunicación colonial. Al pasar de lengua del enemigo al lengua del vencido, el kakán perdió paulatinamente su marco de existencia autónoma.

\footnotetext{
${ }^{97}$ Estela Noli, "Pueblos de indios, indios sin pueblos: los calchaquíes desnaturalizados en la visita de Luján de Vargas de 1693 a San Miguel de Tucumán", Anales Nueva Época, 6, Göteborg, 2003, p. 330-363.

${ }^{98}$ Roxana Boixados y Carlos Zanolli, La visita de Luján de Vargas a las encomiendas de La Rioja y Jujuy (1693-1694), Quilmes, UNQ, 2003

${ }^{99}$ Comparecen por ejemplo el 2 de julio de 1693 en La Rioja Juan Calchaquí y Agustín Mocoví, Ibidem. 2003, p. 70.
} 